\title{
Regional Climate Projections
}

\author{
Robert Vautard
}

\begin{abstract}
When designing adaptation and mitigation measures of climate change for the coming decades and up to the middle of the century, policymakers and industries must rely upon climate information that is an appropriate scale to evaluate impacts, vulnerabilities and risks due to changes in climate. It is, therefore, essential that the quantitative information on the climate and its impacts is reliable. Reliable quantitative information about climate change impacts must also be available. This includes estimations of uncertainty bounds. In the current state of knowledge, technology and structure of scientific communities, climate change impact studies are achieved from a suite of models: global earth system models, with a generally low-resolution $(100-300 \mathrm{~km})$, regional limited-area climate models with a higher resolution $(10-50 \mathrm{~km})$, which take their boundary conditions from global models and impact models calculating how changes in weather, ocean and biogeochemical cycles affect the system to be adapted.
\end{abstract}

Keywords Downscaling • Uncertainty • Extreme events • Climate projections - Scenarios

R. Vautard $(\bowtie)$

Laboratoire des Sciences du Climat et de l'Environnement, Institut Pierre-Simon Laplace, Paris, France

(C) The Author(s) 2018

A. Troccoli (ed.), Weather \& Climate Services for the Energy Industry, https://doi.org/10.1007/978-3-319-68418-5_10 


\section{Regional climate projections}

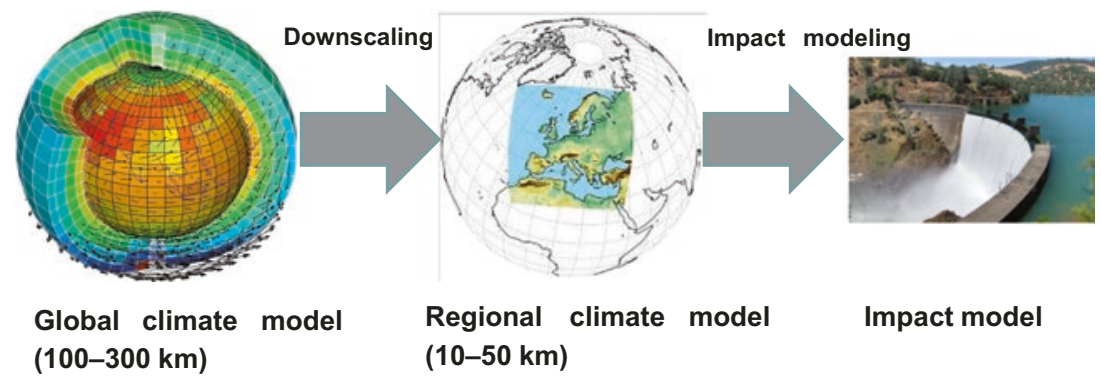

Fig. 10.1 Schematic of the modelling chain used to calculate the impacts of climate change. In this illustration, the impacts can be the river discharge or hydropower potential

\section{INTRODUCTION}

Regional climate projections are the key chain elements that provide information at a scale allowing impacts calculations, and the assessment of adaptation measures. Regional climate projections also allow an improved simulation of physical and biogeochemical processes, and of extreme events at the scales relevant for impacts studies (see schematic of Fig. 10.1).

Uncertainty in climate projections cannot be directly estimated by comparing them against observations, as in the case of weather forecasts, due to the long timescales involved. This is why uncertainty is generally estimated from the spread of ensembles of simulations. The larger the spread, the larger the uncertainty. This emphasizes the need to estimate impacts of climate change using ensembles of models. This section describes ( 1 ) the specific nature of climate projections as compared to forecasts previously presented, their main underlying assumptions, their uncertainty sources and how the science community is organized; (2) how regional climate projections add value to the global climate projections and (3) how they can be used in the energy sector.

\section{What Are Climate Projection and How Do They Differ from Weather Forecasts and Decadal Predictions?}

Climate projections aim at predicting future climatologies, that is, the statistics of weather, of the state of the ocean, cryosphere, vegetation and atmospheric chemical composition. They are based on a number of 
assumptions about human evolution (population, economy, land use, land management, technologies and climate policies) and our understanding of the earth systems response to this evolution. Projections are considered as a "boundary value problem", where climate responds to external drivers. The principle is very different from that of weather forecasts, which is an initial value problem whose aim is to provide a snapshot of the state of the atmosphere at particular points in space and time (see also Chap. 6). Climate projections also differ from weather forecasts in that they use fully fledged earth system models describing the evolution of as many as possible variables concerning all compartments of the earth envelope, for example the ocean, cryosphere, as well as the atmosphere. Weather forecasts, when, for instance, limited to a few weeks, do not need to include changes in the oceans as well as other slowly evolving components of the earth system.

Climate projections also aim at explaining the evolution of past climate, from the instrumental period to paleoclimatic periods. A correct simulation of past periods, including the last century, millennium and beyond (Braconnot et al. 2012) provides some confidence to the models ability to simulate climate change, even though comparison with paleo observations often faces numerous scientific challenges. However, as demonstrated in the fifth assessment report of the IPCC WGI (Intergovernmental Panel on Climate Change Working Group I) (IPCC WGI 2013), climate evolutions along the twentieth century, and in particular the late warming, attributed to human influence on atmospheric composition, are fairly well reproduced: the amplitude of the warming is reproduced as well as the long-term modulations, thought to be due to aerosols.

Climate projections used for adaptation are usually initialized from an equilibrium state in a period when human influence is assumed to be minor relative to external natural forcing (solar and volcanic), in the middle of the nineteenth century. Since the memory of initial conditions disappears quickly, it is therefore not expected that projections synchronously represent the actual chaotic short-term observed evolutions across the instrumental period. Instead, one expects climate projections to represent possible trajectories of the weather, and the probability distribution functions (PDFs) of these fluctuations.

However, models have biases difficult to fully control, because of accumulation of approximations, which are due to low-resolution and insufficiently well-represented physical or biogeochemical processes such as convection or land-atmosphere interactions. In models, all these processes are in a balance that is typically shifted as compared to the real world. However, it is often assumed that such biases do not hinder a correct 
simulation of the response to external forcing. These potential error sources are often called "structural uncertainties".

Two other major sources of uncertainties are also present: the evolution of societies, climate policies and their effect on resulting atmospheric composition (greenhouse gases, aerosols), and on land use. Strong mitigation scenarios, including potential use of negative emission technologies, are likely to significantly alter land use (Smith et al. 2016) and therefore impact climate through an alternative pathway from atmospheric composition. Climate evolutions also undergo a natural internal variability at a timescale of a decade to several decades. Multidecadal modes and oscillations have long been identified (Ghil and Vautard 1991), with yet no full understanding. Such modes can induce temporary warming hiatus such as the one witnessed in the last decade or so. It is considered that the latter uncertainty source dominates for the few coming decades, while uncertainty on scenarios is the dominant driver for the second half of the century.

The global climate projections production that feed the IPCC assessment reports are internationally coordinated by the Climate Model Intercomparison Project (CMIP) (Taylor et al. 2012) supported by the World Climate Research Program. Modelling centres from around the world carry out a core set of simulation using the same natural forcings and socio-economic scenario assumptions. This makes simulations comparable and allows investigation of spread across the different models and some sources of uncertainty to be estimated.

International coordination not only takes place for climate simulations but also for data dissemination through the distributed Earth System Grid Federation (ESGF), with common standards, vocabulary and quality control. The ESGF data nodes ${ }^{1}$, where climate simulations are available from, are part of a gigantic internationally coordinated climate data repository, with a number of functionalities (dynamic catalogue, quick look visualizations etc.). This coordinated effort allows for a systematic retrieval and use of model ensembles in order to account for climate projection uncertainties. The archive is now open to data from a number of projects, namely not just CMIP.

\section{Regional Climate Projections}

After a few pioneering projects such as PRUDENCE (Christensen and Christensen 2007), ENSEMBLES (Hewitt and Griggs 2004) or the North American Regional Climate Change Assessment Program (NARCCAP) (Mearns et al. 2012), regional climate projections were only 
recently coordinated at an international scale within the framework of the COordinated Regional Downscaling Experiment (CORDEX) (Giorgi et al. 2009). This framework aims at providing downscaled global climate projections through a coordinated approach over several regions of the world, using refined, but scale-limited models which take global model output as boundary conditions. A number of regions of the globe are now modelled using this approach, including Europe (Jacob et al. 2014). In Europe, these coordinated projections were made both at a low $(50 \mathrm{~km})$ and high $(12 \mathrm{~km})$ resolutions.

Regional climate projections are issued from limited-area regional climate models (RCMs) (Giorgi and Mearns 1999) which describe weather in a limited area (typically a region of around 25 thousand of kilometres square) with a higher resolution (typically $10-50 \mathrm{~km}$ ) than global climate models (GCMs). These models are often only atmospheric models, forced by sea-surface temperatures and lateral boundary values of temperature, humidity and wind prescribed to be the values obtained from GCMs. Therefore, regional models solve the atmospheric equations with constraints on the boundaries. Recently, regional earth system models are also currently being developed, using ocean coupled with the atmosphere, which is a central development of the MED-CORDEX ${ }^{2}$ project (Ruti et al. 2015).

Just as is true for GCMs, RCMs have inherent climate biases that can be quite large when underpinning processes are poorly constrained by observations. Such is, for instance, the case of heat waves in Europe (Vautard et al. 2013). These biases add to those already present in boundary conditions provided by the GCMs. In particular, providing climate projections at a higher resolution does not annihilate potential biases in large-scale dynamical structures (jet streams, weather patterns), inherited from GCMs.

The expectation, however, is that RCMs better simulate atmospheric flows, and therefore weather, in the vicinity of marked topography or coastal areas, and other small-scale phenomena, compared to GCMs. Heavy precipitations are usually small-scale phenomena, and recent studies show a clear improvement in the statistics of such phenomena (Prein et al. 2016; Giorgi et al. 2016), in particular over mountainous areas, when using high-resolution simulations (e.g. $12 \mathrm{~km}$ as in EUROCORDEX). This has a clear benefit for use in climate projections for studying applications such as winter tourism or mountain ecosystem impacts. By contrast, no added value of higher resolution was found for larger-scale phenomena such as heat waves (Vautard et al. 2013). 
As for GCMs, ensembles of RCMs are assumed to provide a picture of uncertainties in projections. In order to cover a wider range of possibilities, a full GCM-RCM matrix should in principle be explored, each RCM downscaling all GCMs. In practice, while some strategies to explore all combinations have been developed (Mearns et al. 2012), these have not been implemented in practice. As of 2016, the EURO-CORDEX matrix largely remains to be filled for the high-resolution simulations with a $12 \times 12 \mathrm{~km}^{2}$ grid.

Regional climate projections have climatological biases that usually need to be accounted for in impact studies. Bias adjustment is a statistical process that modifies model simulation values in order to adjust distributions to observed values. It uses a range of methods from simple mean bias removal to quantile mapping, in order to adjust the full distribution. More sophisticated schemes account both for past climate corrections and the evolution of distributions as simulated in models, such as the Cumulative Distribution Function transform (CDFt) method (Vrac et al. 2012; Vrac et al. 2016). It is an assumption that bias adjustment does not deteriorate the climate change signal, or even improves projections of changes. However, it is difficult to prove this in practice. It is therefore recommended that climate projections be processed by several bias adjustment methods.

The following example (see data description below) uses the CDFt method to bias adjust the number of rain days according to recent improvements (Vrac et al. 2016) using ten EURO-CORDEX simulations (available from the ESGF archive). Figure 10.2 shows an example of multi-model mean change in daily precipitation amount between the last 30 years of the twenty-first century and the corresponding period of the twentieth century. As an example, a clear, robust signal of precipitation increase is found in Northern Europe, and of precipitation decrease in Southern Europe, where more than eight models agree on the sign of the change.

\section{The Use of Climate Projections for the Energy SECTOR}

Regional climate projections can be used in several ways to help the energy industry and policymakers. Energy demand, renewable energy resources, risks from extreme events, cooling water for thermoelectric generation and other operation conditions all depend on weather and climate. The exposure to weather and climate variability and change will increase in the future decades owing to the tremendous energy transition that is 


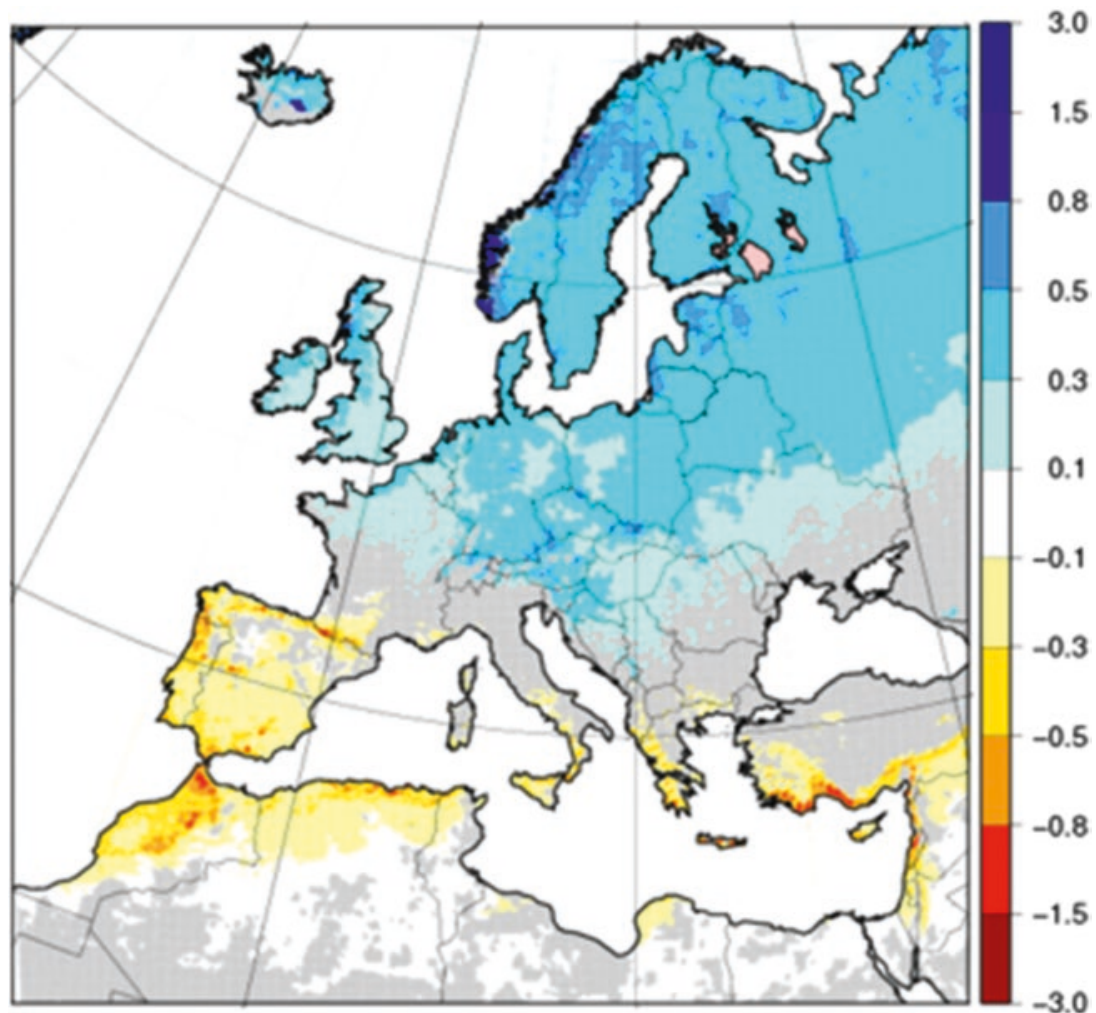

Fig. 10.2 Mean changes in daily precipitation amounts estimated from ten EURO-CORDEX high-resolution model simulations (Jacob et al. 2014), in the RCP8.5 scenario. Changes are measured as differences of mean values calculated over the last 30 years of the twenty-first and twentieth centuries, averaged over the ten projections. Change values, represented by coloured areas, are only displayed when nine or ten models agree on the sign of change. When not, the area is coloured with grey

required to almost completely decarbonize the electricity generation by 2050 in order to reach ambitious climate targets (IPCC WGII 2014).

Both hydropower and thermoelectric generation could be at risk with climate change (van Vliet et al. 2016). In Europe, climate change may be expected to induce rather general decreases in wind power (Tobin et al. 2016), with a higher and more significant signal in Southern Europe (see Fig. 10.3, drawn from the results of the FP7 IMPACT2C project, WP6). 


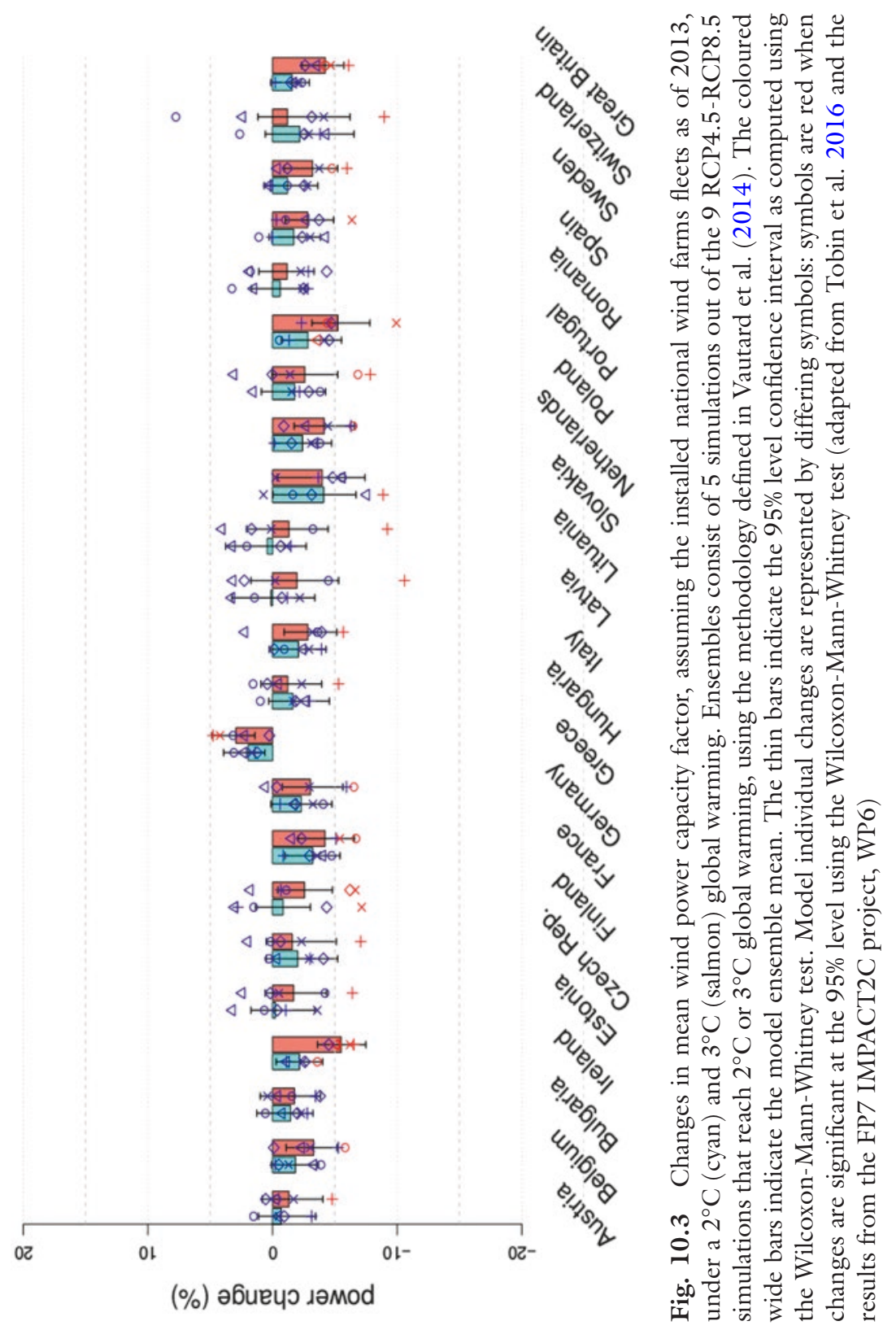


Solar photovoltaic (PV) power may also be expected to decrease in Europe as a result of the analysis of an ensemble of regional climate projections (Jerez et al. 2015).

Climate projections, generally available at the daily timescale, and in some cases at sub-daily timescale, can also be used as "weather generators". Bias-adjusted time series obtained from ensembles of simulations are usually 10-30 times longer than observed time series, due to the number of models available and do not suffer from homogeneity problems. They can generate statistics dedicated to the user's problem, such as the risk of typical extreme events. In some cases, infrastructures are built to cope with reference events, such as, for instance, extreme cold spells (e.g. winter of 1963) that occurred in the past. The risk of such events in current and future climates can be evaluated from the climate projection ensembles time series, although this is still a developing science. Reference events and their odds in the current and future climate can provide concrete information for adaptation.

For the needs of the energy sector, dedicated regional climate projections data sets have been developed and made available through prototype "climate services", such as, for Europe, CLIM4ENERGY ${ }^{3}$ and European Climatic Energy Mixes (ECEM) ${ }^{4}$ Copernicus Climate Change Service projects. Other data sets for other regions (e.g. NARCCAP data for North America $^{5}$ ) are also available to be used for application in the energy sector. The value of such datasets for adaptation needs is still to be assessed by users as their use is relatively new.

\section{Notes}

1. See e.g. http://esgf-node.ipsl.upmc.fr/.

2. MED-CORDEX is the name of the experiment, and stands for Mediterranean.

3. http://clim4energy.climate.copernicus.eu

4. http://ecem.climate.copernicus.eu

5. http://www.narccap.ucar.edu/

\section{REFERENCES}

Braconnot, P., Harrison, S. P., Kageyama, M., Bartlein, P. J., Masson-Delmotte, V., Abe-Ouchi, A., et al. (2012). Evaluation of climate models using palaeoclimatic data. Nature Climate Change, 2(6), 417-424.

Christensen, J. H., \& Christensen, O. B. (2007). A summary of the PRUDENCE model projections of changes in European climate by the end of this century. Climatic change, 81(1), 7-30. 
Ghil, M., \& Vautard, R. (1991). Interdecadal oscillations and the warming trend in global temperature time series. Nature, 350, 324-327.

Giorgi, F., \& Mearns, L. O. (1999). Introduction to special section: Regional climate modeling revisited. Journal of Geophysical Research: Atmospheres, 104(D6), 6335-6352.

Giorgi, F., Jones, C., \& Asrar, G. R. (2009). Addressing climate information needs at the regional level: The CORDEX framework. World Meteorological Organization (WMO) Bulletin, 58(3), 175.

Giorgi, F., Torma, C., Coppola, E., Ban, N., Schär, C., \& Somot, S. (2016). Enhanced summer convective rainfall at Alpine high elevations in response to climate warming. Nature Geoscience. https://doi.org/10.1038/ngeo2761.

Hewitt, C. D., \& Griggs, D. J. (2004). Ensembles-based predictions of climate changes and their impacts (ENSEMBLES). Eos, 85(52), 566.

IPCC. (2013). Climate change 2013: The physical science basis (T. F. Stocker et al., Eds.). New York: Cambridge University Press.

IPCC, WGII: Mach, K., \& Mastrandrea, M. (2014). Climate change 2014: Impacts, adaptation, and vulnerability (Vol. 1). C. B. Field \& V. R. Barros (Eds.). Cambridge and New York: Cambridge University Press.

Jacob, D., Petersen, J., Eggert, B., Alias, A., Christensen, O. B., Bouwer, L. M., et al. (2014). EURO-CORDEX: New high-resolution climate change projections for European impact research. Regional Environmental Change, 14, $563-578$.

Jerez, S., Tobin, I., Vautard, R., Montávez, J. P., López-Romero, J. M., Thais, F., et al. (2015). The impact of climate change on photovoltaic power generation in Europe. Nature Communications. https://doi.org/10.1038/ncomms10014.

Mearns, L. O., Arritt, R., Biner, S., Bukovsky, M. S., McGinnis, S., Sain, S., et al. (2012). The North American regional climate change assessment program: Overview of phase I results. Bulletin of the American Meteorological Society, 93(9), 1337-1362.

Prein, A., Gobiet, A., Truehetz, H., Keuler, K., Goergen, K., Teichmann, C., et al. (2016). Precipitation in the EURO-CORDEX $0.11^{\circ}$ and $0.44^{\circ}$ simulations: High resolution, high benefits? Climate Dynamics, 46(1-2), 383-412.

Ruti, P., Somot, S., Dubois, C., Calmanti, S., Ahrens, B., Alias, A., et al. (2015). MED-CORDEX initiative for Mediterranean climate studies. Bulletin of the American Meteorological Society, 97, 1175.

Smith, P., Davis, S. J., Creutzig, F., Fuss, S., Minx, J., Gabrielle, B., et al. (2016). Biophysical and economic limits to negative $\mathrm{CO}_{2}$ emissions. Nature Climate Change, 6(1), 42-50.

Taylor, K. E., Stouffer, R. J., \& Meehl, G. A. (2012). An overview of CMIP5 and the experiment design. Bulletin of the American Meteorological Society, 93(4), 485-498. 
Tobin, I., Jerez, S., Vautard, R., Thais, F., Déqué, M., Kotlarski, S., et al. (2016). Climate change impacts on the power generation potential of a European midcentury wind farms scenario. Environ. Res. Lett., 11(3), 034013.

Vautard, R., Gobiet, A., Jacob, D., Belda, M., Colette, A., Déqué, M., et al. (2013). The simulation of European heat waves from an ensemble of regional climate models within the EURO-CORDEX project. Climate Dynamics, 41, $2555-2575$.

Vautard, R., Gobiet, A., Sobolowski, S., Kjellström, E., Stegehuis, A., Watkiss, P., et al. (2014). The European climate under a $2^{\circ} \mathrm{C}$ global warming. Environmental Research Letters. https://doi.org/10.1088/1748-9326/9/3/034006.

van Vliet, M. T. H., Wiberg, D., Leduc, S., \& Riahi, K. (2016). Power-generation system vulnerability and adaptation to changes in climate and water resources. Nature Climate Change, 6(4), 375-380.

Vrac, M., Drobinski, P., Merlo, A., Herrmann, M., Lavaysse, C., Li, L., et al. (2012). Dynamical and statistical downscaling of the French Mediterranean climate: Uncertainty assessment. Natural Hazards and Earth System Sciences, 12, 2769-2784.

Vrac, M., Noël, T., \& Vautard, R. (2016). Bias correction of precipitation through Singularity Stochastic Removal: Because occurrences matter. Journal of Geophysical Research, 121, 5237-5258.

Open Access This chapter is distributed under the terms of the Creative Commons Attribution 4.0 International License (http://creativecommons.org/licenses/ by $/ 4.0 /$ ), which permits use, duplication, adaptation, distribution and reproduction in any medium or format, as long as you give appropriate credit to the original author(s) and the source, a link is provided to the Creative Commons license and any changes made are indicated.

The images or other third party material in this chapter are included in the work's Creative Commons license, unless indicated otherwise in the credit line; if such material is not included in the work's Creative Commons license and the respective action is not permitted by statutory regulation, users will need to obtain permission from the license holder to duplicate, adapt or reproduce the material.

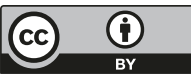

